\title{
Tyler asbestos workers: mortality experience in a cohort exposed to amosite
}

\author{
Jeffrey L Levin, Jerry W McLarty, George A Hurst, Angela N Smith, Arthur L Frank
}

\begin{abstract}
Objectives-To examine the causes of death among 1130 former workers of a plant in Tyler, Texas dedicated to the manufacture of asbestos pipe insulation materials. This cohort is important and unusual because it used amosite as the only asbestiform mineral in the production process. High level exposure of such a specific type was documented through industrial hygiene surveys in the plant.

Methods-Deaths were ascertained through various sources including data tapes from the Texas Department of Health and the national death index files. As many death certificates as possible were secured (304/315) and cause of death assigned. After select exclusions, 222 death certificates were used in the analysis. Causes of death were compared with age, race, and sex specific mortalities for the United States population with a commercial software package (OCMAP Version 2.0).
\end{abstract}

Results-There was an excess of deaths from respiratory cancer including the bronchus, trachea, and lung (standardised mortality ratio (SMR) 277 with $95 \%$ confidence interval (95\% CI) 193 to 385$)$. Four pleural mesotheliomas and two peritoneal mesotheliomas were identified. The analysis also showed an increasing risk of respiratory malignancy with increased duration of exposure including a significant excess of total deaths from respiratory cancer with less than six months of work at the plant (SMR 268 with $95 \%$ CI 172 to 399 ).

Conclusions-The importance of the cohort lies with the pure amosite exposure which took place in the plant and the extended period of latency which has followed. The death certificate analysis indicates the pathogenicity of amosite, the predominant commercial amphibole used in the United States. These data confirm a link between amosite asbestos and respiratory malignancy as well as mesothelioma.

(Occup Environ Med 1998;55:155-160)

Keywords: Tyler; amosite; asbestos; cancer; mesothelioma

Numerous articles have been written on the health effects of exposure to asbestos. Studies have continued to confirm that asbestos is a cause of malignant and non-malignant disease. ${ }^{1}$ None the less, controversy surrounding the relative pathogenicity of different types of asbestos for causing these various diseases persists. ${ }^{23}$ It is also important to recognise that circumstances of exposure to hazardous materials in various occupational and environmental settings may contribute to relative pathogenicity.

Many data have been obtained on people exposed to crocidolite, ${ }^{4-6}$ as well as some comparative data evaluating mortality in amphibole miners exposed to crocidolite and amosite. ${ }^{7}$ However, amosite has been considered the amphibole of particular importance in the United States, ${ }^{4}$ with imports and usage rising sharply during and after the second world war. ${ }^{8}$ Amosite is a major residual fibre in people with heavy exposure to chrysotile and amosite. ${ }^{9}$ It has been shown to be the predominant commercial asbestiform fibre in a series of cases in the United States with mesothelioma. ${ }^{10}$ Likewise, in the United States, amosite is the predominant asbestos fibre as the core of ferruginous bodies in people with tissue burdens above environmental levels. ${ }^{11}$

Given that commercial amphiboles, particularly amosite, are dispersed within various environmental and occupational settings within our society, an understanding of the morbidity and mortality associated with exposure to amosite is critical. Yet there are very few published studies of work settings in which amosite was the exclusive form of asbestos used.

Acheson et al reported on the mortality experience of 5969 men employed in a factory that used amosite asbestos from 1947 to $1979 .{ }^{12}$ Although amosite was the predominant fibre type, short chrysotile was added in limited quantities accompanied by experimental use of crocidolite on several occasions.

Two other retrospective studies of a plant in Patterson, New Jersey have also been published. ${ }^{8}{ }^{13}$ This plant manufactured amosite asbestos insulation for the United States Navy during the second world war, primarily for use in shipbuilding and repair. Nine hundred and thirty three men were employed in the plant for varying periods between June 1941 and December 1945. These two studies reported many mesotheliomas and an increased risk of lung cancer. The more recent analysis showed an excess risk of lung cancer with employment as short as one month and increasing with duration of exposure. Furthermore, the latency of lung cancer was shortened for those with longer employment as well as among people who were older at first onset of exposure. Of note is that Selikoff et al also reported an excess 
Tyler asbestos workers

securing death certificates

(1130 workers)

Texas Department of Health tapes

Texas driver's licence files

Deaths at University of Texas Health Center at Tyler

Family contacts, obituary notices

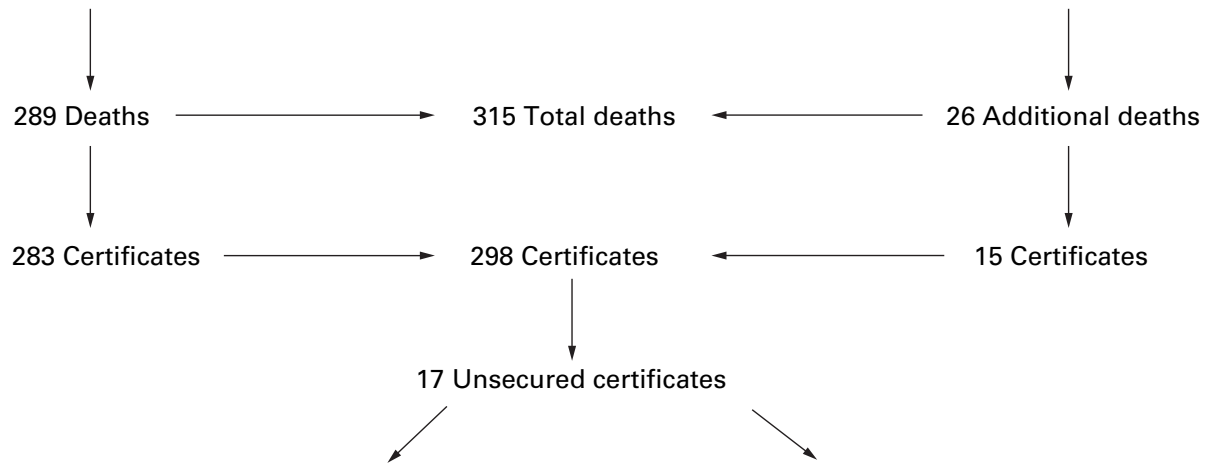

4 Died before 1979
Equifax Government and Special Systems, 856 names submitted

Alive or vital status unknown

Death certificate unavailable

State (location) of death unknown
13 Names submitted to national death index search for state (location) of death

6 Certificates

Total death certificates $=304$

Figure 1 Flow diagram depicting approach to determining number of deaths and securing death certificates.

of deaths from cancers of various gastrointestinal structures. ${ }^{8}$

The factory in Patterson was closed in 1954. Although actual environmental data are lacking on the Patterson plant, estimates have been made with mean exposures ranging from 14 to 75 fibres $/ \mathrm{ml}^{14}$ The Patterson plant was the predecessor to the plant in the present study, and used some of the same equipment and raw materials. ${ }^{15}$

The Tyler asbestos plant manufactured asbestos pipe insulation from 1954 to February of 1972, when it closed after citations from the Occupational Safety and Health Administration (OSHA) about exposure levels in excess of the regulatory standard. ${ }^{16}$ The amosite asbestos was obtained from the Transvaal region of South Africa. The insulation product was manufactured from a mixture of about $90 \%$ amosite and varying amounts of diatomaceous earth, sodium silicate, and mineral wool. Other details of the manufacturing process have been reported elsewhere. ${ }^{1516}$ Three environmental surveys of plant operations were conducted, in 1967,1970 , and 1971, with average fibre concentrations ranging from 15.9 to 91.4 fibres/ $\mathrm{ml}$. The respirator programme was deemed inadequate and the wearing of respirators was not made mandatory until 1971 , just before the plant closed. ${ }^{17}$

The uniqueness of this asbestos cohort lies with the fact that people working in the Tyler plant were from a rural environment, sheltered from adjacent industrial complexes, and exposed to a single asbestiform mineral during plant operations. The cohort also represents one of the few, if not the only study group of this nature, for which actual industrial hygiene measurements documenting exposure exist and considerable medical surveillance has been carried out. The following mortality analysis, some 30 years after the site first opened, is submitted from one of the cohorts most purely exposed to amosite that we know of.

\section{Methods}

With available microfilmed employment records, the Biometry Branch of the National Institutes of Occupational Safety and Health (NIOSH) developed a master computer file of 878 current and former workers for the original Tyler asbestos workers program (TAWP). ${ }^{15}$ There were also 165 workers from a temporary agency who received intermittent exposure unloading the amosite from the railway wagons. ${ }^{15}$ These workers were identified by a regional poll of temporary agencies after the NIOSH visit and as part of the TAWP. Dates of employment were available from the temporary agency. There were also workers from clean up crews who were employed after the plant closed. These subjects and other former employees of the plant not on the NIOSH master file were subsequently added as they were identified. Fifty two of these people were added by 31 May $1978 . .^{15} \mathrm{Up}$ to December 1993, 35 more people presented themselves as part of the cohort, in response to various forms of publicity related to the TAWP, which were used to find as many subjects as possible who had worked at the plant. Employment was verified if possible by interview and available documentation. These employees worked in production jobs similar to those identified in 
Tyler asbestos workers

exclusions for mortality analysis
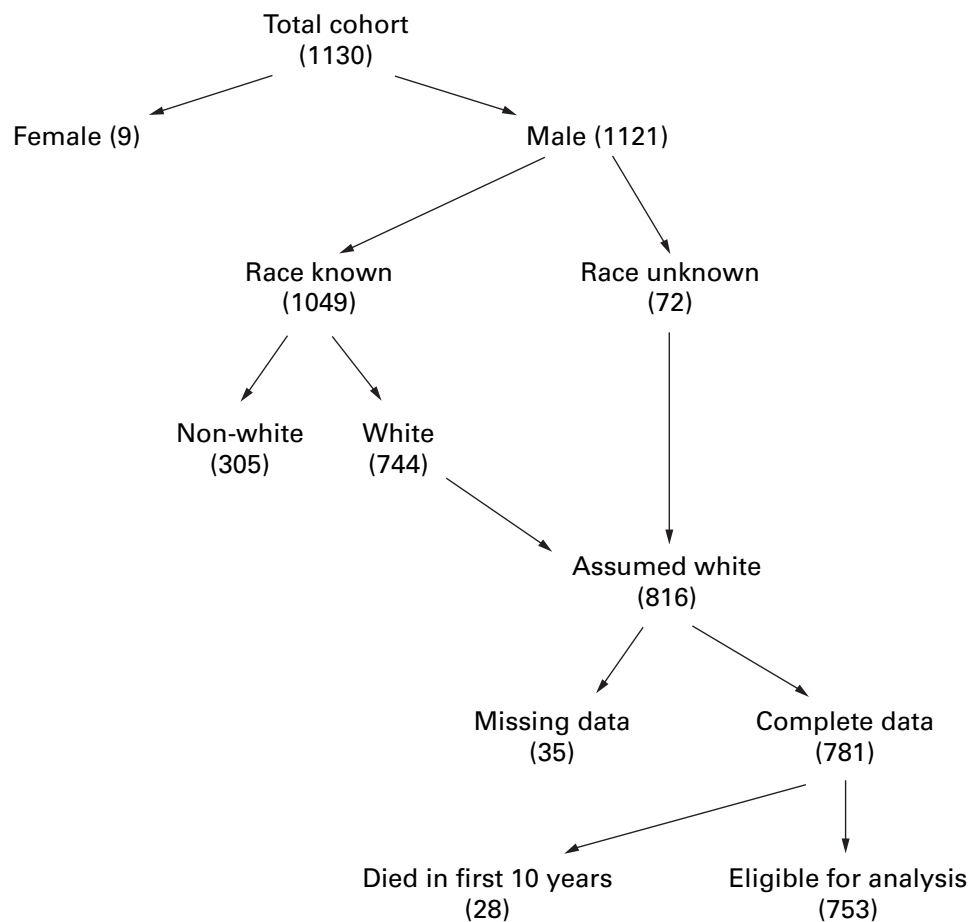

(28)

(753)

Figure 2 Flow diagram summarising exclusions for mortality analysis.

the NIOSH master file, or sustained occupational exposure to asbestos at the plant. The cohort on which this mortality study is based was made up of 1130 workers.

Demographically, there were 1121 men and nine women. All of the women were white and were clerical workers. They were excluded from the analysis because of their small number. Of the men, 744 were white, 305 nonwhite (includes 301 black, two Hispanic, and two other), and there were 72 for whom race was missing on employment records. For the purposes of the analysis, they were assumed to be white because of the date of hiring and hiring practices. Namely, minorities were excluded from hiring into production jobs until after the plant was unionised in 1962. With this assumption, altogether, there were $73 \%$ white and $27 \%$ non-white workers. Eighty one per cent of workers were noted to be current or ex-smokers.

The median age at hire was 25 years. The duration of employment ranged from one day to 17.3 years with a mean of 12.7 months and median of 1.6 months. These data are based on information from 1090 workers with complete employment records.

Deaths were determined primarily through a collection of data tapes available through the Texas Department of Health containing all recorded deaths in the state for each year since 1960. A few deaths $(<20)$ were identified through family contacts, obituary notices, or by their occurrence at The University of Texas Health Center at Tyler. Other record sources such as the Texas driver's licence files were also searched. When matched with the cohort data- base, 289 deaths were identified through these methods. For most deaths (known to have occurred in Texas), certificates were easily available through the Texas Bureau of Vital Statistics.

In 1993, a total of 856 social security numbers were submitted to Equifax Government and Special Systems to uncover additional deaths or determine the state in which the deaths occurred for people known to have died and for whom certificates were not available. Equifax is a private firm which maintains death files since 1955 through continuous updates provided from the United States Social Security Administration. Twenty six additional deaths, previously unknown, were identified through this method, totalling 315 dead from the initial cohort.

Following this search, 17 certificates remained unsecured because of unknown location of death. Thirteen of these were submitted to the National Center for Health Statistics for comparison against their records. The remaining four were known to have died before 1979, the earliest year of the national death index files. In total, 304 death certificates $(96.5 \%$ of the 315 known dead) were secured for this study. Figure 1 depicts a flow diagram outlining the steps involved in determining the number of deaths and securing death certificates.

Each certificate was reviewed by an epidemiologist and coded from the international classification of diseases. ${ }^{18}$ They were then jointly reviewed by the same epidemiologist and an occupational medicine physician with a mutually agreed upon cause of death assigned. The underlying cause of death was defined as "the disease or injury which initiated the train of events leading directly to death."19

The data were analysed with OCMAP Version $2.0^{20}$ which employs mortality and population data system (MPDS) rates available from the University of Pittsburgh, Department of Biostatistics (containing over 110 million records from detailed mortality tapes provided by the Environmental Protection Agency and the National Center for Health Statistics). Age, race, and sex specific mortalities for all states and counties in the United States are available through the MPDS system for the years 1950-86 for malignant neoplasms and for the years 1962-86 for all non-malignant causes of death. Standard mortality ratios (SMR) were derived by comparing cause specific deaths observed to expected numbers of deaths for all states calculated based on sex, race, and person-years at risk accumulated by the study cohort, and with five-year age and time specific intervals. Consideration of period allows for comparison of observed to expected deaths during that period as well as allowing the worker to move from shorter durations to a maximum duration of exposure.

The observed numbers of deaths were assumed to follow a Poisson distribution and 95\% confidence intervals (95\% CIs) were calculated. Deviations of the SMR above 100 were considered to be significant for an excess 
Table 1 SMR analysis for selected causes of death

\begin{tabular}{|c|c|c|c|c|}
\hline Cause of death (ICDA-9 classifications) & $O b s$ & $\operatorname{Exp}$ & $S M R$ & $95 \% C I$ \\
\hline All causes of death ${ }^{\star}$ & 222 & 133.6 & 166 & 145 to 190 \\
\hline All malignant neoplasms & 78 & 33.7 & 231 & 183 to 289 \\
\hline Buccal cavity and pharynx & 1 & 0.9 & 107 & 3 to 595 \\
\hline Digestive organs and peritoneum & 16 & 8.1 & 197 & 113 to 320 \\
\hline Oesophagus & 2 & 0.9 & 232 & 28 to 839 \\
\hline Stomach & 0 & 1.1 & - & - \\
\hline Large intestine & 6 & 2.9 & 207 & 76 to 451 \\
\hline Rectum & 0 & 0.7 & - & - \\
\hline Biliary passages and liver & 2 & 0.7 & 306 & 37 to 11034 \\
\hline Pancreas & 3 & 1.7 & 179 & 37 to 523 \\
\hline All other digestive organs & $3 \dagger$ & 0.02 & 1360 & 281 to 3974 \\
\hline Respiratory system & 40 & 13.2 & 302 & 216 to 412 \\
\hline Larynx & 1 & 0.5 & 221 & 6 to 1229 \\
\hline Bronchus, trachea, lung & 35 & 12.6 & 277 & 193 to 385 \\
\hline All other respiratory & $4 \ddagger$ & 0.1 & 2881 & 785 to 7377 \\
\hline Prostate (men only) & 1 & 1.9 & 54 & 1 to 300 \\
\hline Malignant melanoma of skin & 1 & 0.7 & 151 & 4 to 840 \\
\hline Central nervous system & 3 & 1.1 & 273 & 56 to 799 \\
\hline All lymphatic, haematopoietic tissue & 6 & 3.2 & 191 & 70 to 415 \\
\hline All other malignant neoplasms & 10 & 2.7 & 372 & 178 to 684 \\
\hline Benign neoplasms & 1 & 0.4 & 260 & 7 to 1446 \\
\hline Cerebrovascular disease & 13 & 5.9 & 221 & 117 to 377 \\
\hline All heart disease & 60 & 50.8 & 118 & 90 to 152 \\
\hline Hypertension without heart disease & 2 & 0.3 & 659 & 80 to 2382 \\
\hline Non-malignant respiratory disease & 18 & 8.3 & 218 & 129 to 344 \\
\hline Influenza and pneumonia & 4 & 2.5 & 162 & 44 to 415 \\
\hline Bronchitis, emphysema, and asthma & 1 & 1.9 & 54 & 1 to 301 \\
\hline Other non-malignant respiratory disease & $13 \sqrt{3}$ & 3.9 & 330 & 176 to 564 \\
\hline Cirrhosis of liver & 3 & 4.2 & 72 & 15 to 211 \\
\hline Nephritis and nephrosis & 1 & 0.8 & 132 & 3 to 733 \\
\hline All external causes of death & 19 & 13.6 & 140 & 84 to 219 \\
\hline All other causes of death & 19 & 13.0 & 146 & 88 to 228 \\
\hline Unknown causes (also in all causes category) & 8 & & & \\
\hline
\end{tabular}

Obs $=$ observed deaths $; \operatorname{Exp}=$ expected deaths; SMR $=100^{\star}$ Obs $/$ Exp.

*Deaths that occurred within 10 years of first exposure are excluded from the SMR analysis.

tIncludes two deaths from peritoneal mesothelioma and one from jejunal cancer.

$\ddagger$ All four are deaths from pleural mesothelioma.

Includes three deaths from asbestosis.

IIncludes accidents, suicides, homicides, and other external causes.

number of deaths if the $95 \%$ CIs were noted to be $>100$.

Person-years at risk were calculated from the date of first employment at the asbestos manufacturing plant as the starting date, and date of last contact as the ending date. Workers with missing employment dates and missing birth dates were excluded ( 35 workers). If mortality status was not known, subjects were assumed to be alive, thus contributing to the personyears at risk calculation for expected number of deaths. This would result in a conservative bias to the SMR by overestimating the expected number of deaths. The ending date of work (from available employment records) was used to determine duration of exposure.

Finally, because of the predominance of white men in the study population and later integration of other people to the plant, black men and women were excluded from this statistical analysis and will be evaluated separately in the future. Furthermore, because several years are required for the development of asbestos related disease, the mortality analysis follow up period was chosen to start at 10 years from first employment. For cancer mortality, this would offer a realistic estimate of risk. Hence, those people who died with $<10$ years of latency (totalling 28 deaths) were completely excluded from the mortality analysis, as well as from the calculation of person-years at risk.

After excluding black men, all women, workers with missing employment dates, and missing birth dates, and deaths with $<10$ years of latency, 753 workers remained for mortality analysis. Two hundred and twenty two deaths were recorded among this group. Figure 2 depicts a flow diagram summarising these exclusions.

\section{Results}

Among the 222 deaths in the analytical group, the average age at death was 60 years. The expected mean age of death for this group is 59.2 years.

Table 1 shows the results of the mortality analysis. A highly significant number of excess deaths were found for all causes; for all malignant neoplasms; for cancers of the respiratory system as a whole, lung cancer, and other respiratory cancers; for other malignant neoplasms; and for non-malignant respiratory diseases. The category of other non-malignant respiratory causes of death includes three deaths due to asbestosis, but underestimates the total number of cases of asbestosis still living, or which may have died of a concurrent malignancy. A significant excess of mortality due to malignant neoplasms of the digestive organs and peritoneum was also noted.

There were six deaths from mesothelioma: four pleural and two peritoneal. This constitutes about $3 \%$ of all deaths. These are included, but not explicitly shown in table 1 because of the classification scheme used ("other" respiratory and digestive malignancies). Excess cancers were found for most other sites, but were not significant.

Table 2 compares observed and expected deaths from respiratory cancer by duration of exposure and time since first exposure (latency). Deaths from respiratory cancer become 
Table 2 Deaths from respiratory cancer: observed and expected deaths and SMR by duration of exposure and time since first exposure

\begin{tabular}{|c|c|c|c|c|c|}
\hline \multirow[b]{2}{*}{ Latency $(y)$} & \multicolumn{5}{|c|}{ Duration of exposure } \\
\hline & $<6$ months & 6-12 months & $1-5 y$ & $>5 y$ & Total \\
\hline \multicolumn{6}{|l|}{ 10-15: } \\
\hline Obs & 0 & 0 & 0 & 0 & 0 \\
\hline Exp & 0.8 & 0.1 & 0.02 & 0.2 & 1.3 \\
\hline SMR & - & - & - & - & - \\
\hline \multicolumn{6}{|l|}{ 15-20: } \\
\hline Obs & 5 & 1 & 0 & $2^{\star}$ & 8 \\
\hline Exp & 1.3 & 0.2 & 0.3 & 0.3 & 2.1 \\
\hline SMR & 385 & 562 & 119 & 754 & 391 \\
\hline $95 \% \mathrm{CI}$ & (125 to 898$)$ & (14 to 3132$)$ & (0 to 1205 ) & (91 to 2724 ) & (169 to 770 ) \\
\hline \multicolumn{6}{|l|}{ 20-25: } \\
\hline Obs & 7 & 0 & 1 & 3 & 11 \\
\hline Exp & 1.8 & 0.3 & 0.04 & 0.3 & 2.8 \\
\hline SMR & 391 & - & 254 & 977 & 399 \\
\hline $95 \% \mathrm{CI}$ & (157 to 807 ) & - & (6 to 1412 ) & (202 to 2855 ) & (199 to 714 ) \\
\hline \multicolumn{6}{|l|}{$>25:$} \\
\hline Obs & $12^{\star}$ & 2 & $5+$ & 2 & 21 \\
\hline Exp & 5.0 & 0.5 & 0.9 & 0.07 & 7.1 \\
\hline SMR & 238 & 410 & 557 & 284 & 294 \\
\hline $95 \% \mathrm{CI}$ & (123 to 416$)$ & (50 to 1481 ) & (181 to 1301$)$ & (34 to 1027 ) & (182 to 450$)$ \\
\hline \multicolumn{6}{|l|}{ Total: } \\
\hline Obs & 24 & 3 & 6 & 7 & 40 \\
\hline Exp & 8.9 & 1.1 & 1.8 & 1.5 & 13.2 \\
\hline SMR & 268 & 286 & 336 & 481 & 302 \\
\hline $95 \% \mathrm{CI}$ & (172 to 399$)$ & (59 to 835 ) & (123 to 732 ) & (193 to 990$)$ & (216 to 412$)$ \\
\hline
\end{tabular}

*Includes one death from pleural mesothelioma.

†Includes two deaths from pleural mesothelioma.

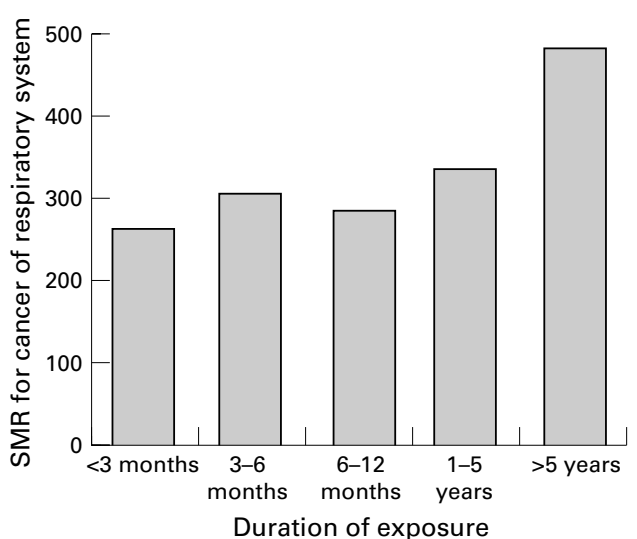

Figure 3 SMRs for cancer of the respiratory system by duration of exposure. Test for trend in mortality (deaths from cancer of the respiratory system $v$ all other deaths) with increasing duration of exposure: $\chi^{2}=3.9, p<0.05$.

significant as early as 15 years after onset of exposure. Exposure durations of less than six months resulted in a significant excess of deaths from respiratory cancer. Furthermore, an apparent increasing trend of total respiratory cancer deaths was found for increased duration of exposure.

Figure 3 examines SMRs for cancers of the respiratory system based on duration of exposure at the plant. A gradient was found between the group with less than three months of exposure and the group with three to six months of exposure. Testing for trend in mortality with increasing duration of exposure was significant at $\mathrm{p}<0.05$.

\section{Discussion}

This study supports a significant excess of deaths from respiratory cancers, mesothelioma, and asbestosis due to exposure to amosite. This is not surprising given the mortality experience of the Patterson cohort and documented high levels of exposure at the Tyler plant.
We recognise the inherent limitations of using causes of death on death certificates for determining mortality, as well as the potential for introduction of selection bias based upon incomplete employment records. However, attempts were made to limit this bias by tracing as many employees as possible and by excluding individual workers without employment dates. Furthermore, the contribution to person-years at risk from people with known employment dates, but for whom mortality status was uncertain, results in an underestimation of actual deaths attributable to exposure. None the less, significant excesses in mortality were noted. One final note is made of the inability to control for smoking as a possible contributor to cause specific mortality, as the smoking status of all people was not known. Given the incomplete information available on smoking as well as the limited information available on earlier and subsequent exposures to asbestos and other agents, the potential for an excess bias for respiratory malignancy exists.

Despite these factors, the importance of showing excess deaths in this group from respiratory cancers, mesotheliomas, and nonmalignant forms of disease related to asbestos should not be understated. Smoking has not been shown to influence the risk of mesothelioma from exposure to asbestos and many people in the cohort are just now entering the most critical period after exposure for highest risk of developing this and other cancers $(>30$ years). ${ }^{1}$ Furthermore, a significant rate of deaths from respiratory cancer with less than six months of exposure, as well as an apparent dose-response relation with a detectable gradient at less than three months of exposure, were shown by this analysis. Although there may be other factors contributing to risk of respiratory cancer, these findings make it difficult not to be convinced that exposure to 
amosite in this cohort is largely responsible for excess deaths from lung cancer. These are important findings, given the unique nature of the exposure in this plant exclusively to amosite, and its current recognition as the predominant amphibole used in the United States.

The Tyler cohort still has time to "mature" with many deaths yet to come. It is expected that further deaths from respiratory cancer and mesothelioma will occur as the latency period lengthens further. The mortality experience of this group will be followed with interest, given the uniqueness of this plant as one of the most pure exposures to amosite that we know of.

1 Selikoff IJ, Seidman H. Asbestos-associated deaths among insulation workers in the United States and Canada, 1967insulation workers in the United States
87. Ann NY Acad Sci 1991;643:1-14.

2 Mossman BT, Gee JBL. Asbestos-related diseases. $N$ Engl $\mathcal{F}$ Med 1989;320:1721-30.

3 Stayner LT, Dankovic DA, Lemen RA. Occupational exposure to chrysotile asbestos and cancer risk: a review of the amphibole hypothesis. Am f Public Health 1996;86:179-86.

4 Wagner JC. Mesothelioma and mineral fibers. Cancer 1986; 57:1905-11

5 Wagner JC, Pooley FD. Mineral fibres and mesothelioma. Thorax 1986;41:161-6.

6 Wagner JC. The discovery of the association between blue asbestos and mesotheliomas and the aftermath. $\mathrm{Br} \mathcal{F}$ Ind Med 1991;48:399-403.

7 Sluis-Cremer GK, Liddell FDK, Logan WPD, et al. The mortality of amphibole miners in South Africa, 1946-80. BrF Ind Med 1992;49:566-75.

8 Selikoff IJ, Hammond EC, Churg J. Carcinogenicity of amosite asbestos. Arch Environ Health 1972;25:183-6.
9 Churg A, Vedal S. Fiber burden and patterns of asbestosrelated disease in workers with heavy mixed amosite and related disease in workers with heavy mixed amosite and
chrysotile exposure. Am $\mathcal{7}$ Respir Cell Mol Biol 1994;150: 663-9.

10 Dodson RF, O'Sullivan MF, Corn CJ, et al. Analysis of asbestos fiber burden in lung tissue from mesothelioma patients. Ultrastruct Pathol 1997;21:321-36.

11 Dodson RF, O'Sullivan MF, Corn CJ. Relationships between ferruginous bodies and uncoated asbestos fibers in lung tissue. Arch Environ Health 1996;51:462-6.

12 Acheson ED, Gardner MJ, Winter PD, et al. Cancer in a factory using amosite asbestos. Int $\mathcal{F}$ Epidemiol 1984;13:310 .

13 Seidman H, Selikoff IJ, Hammond EC. Short-term asbestos work exposure and long-term observation. Ann NY Acad Sci 1979;330:61-89.

14 Lemen RA, Dement JM, Wagoner JK. Epidemiology of asbestos-related diseases. Environ Health Perspect 1980;34: $1-11$

15 Hurst GA, Spivey CG, Matlage WT, et al. The Tyler asbestos workers program: I. A medical surveillance model and method. Arch Environ Health 1979;34:432-9.

16 Johnson WM, Lemen RA, Hurst GA, et al. Respiratory morbidity among workers in an amosite asbestos insulation plant. 7 Occup Med 1982;24:994-9.

17 Anania TL, Johnson WM. Asbestos survey, Pittsburgh-Corning Corporation, Tyler, Texas, October 26-29, 1971. Cincinnati: Narional Institute for Occupational Safety and Health, 7 December, 1971. (NIOSH Project No 71-45.)

18 Jones $\mathrm{M}$, Allen $\mathrm{M}$, Brouch $\mathrm{K}$, et al, eds. International

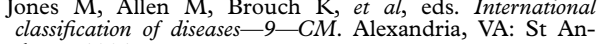
thony, 1991

19 National Center for Health Statistics. Vital statistics of the United States, 1980. Vol II. Mortality, part A, technical appendix, section 7. Washington, DC: US Government Printing Office, Public Health Service, 1985:7. (DHHS Pub No (PHS) 85-1101.)

20 Marsh G, Preininger M, Ehland J, et al. OCMAP OCMAP/PC mainframe and microcomputer version 2.0 user manual, 2nd ed. Pittsburgh: University of Pittsburgh, Graduate School of Public Health, Department of Biostatistics; $1989: 4-1$ to $4-2$, A-2 to A-3.

\section{Vancouver style}

All manuscripts submitted to Occup Environ Med should conform to the uniform requirements for manuscripts submitted to biomedical journals (known as the Vancouver style.)

Occup Environ Med, together with many other international biomedical journals, has agreed to accept articles prepared in accordance with the Vancouver style. The style (described in full in the $\mathcal{F} A M A[1]$ ) is intended to standardise requirements for authors, and is the same as in this issue.

References should be numbered consecutively in the order in which they are first mentioned in the text by Arabic numerals on the line in square brackets on each occasion the reference is cited (Manson[1] confirmed other reports[2][3][4][5]). In future references to papers submitted to Occup Environ Med should include: the names of all authors if there are three or less or, if there are more, the first three followed by et al; the title of journal articles or book chapters; the titles of journals abbreviated according to the style of Index Medicus; and the first and final page numbers of the article or chapter. Titles not in Index Medicus should be given in full. are:

Examples of common forms of references

1 International Committee of Medical Journal Editors. Uniform requirements for manuscripts submitted to biomed journals. $\mathcal{F} A M A$ 1993;269:2282-6.

Soter NA, Wasserman SI, Austen KF. Cold urticaria: release into the circulation of histmaine and eosinophil chemotactic factor of anaphylaxis during cold challenge. N Engl F Med 1976;294:687-90.

3 Weinstein L, Swartz MN. Pathogenic properties of invading micro-organisms. In: Sodeman WA Jr, Sodeman WA, eds. Pathologic physiology, mechanisms of disease. Philadelphia: W B Saunders, 1974:457-72. 